\title{
Congenital urethral fistula
}

\section{T L A Janath Kumara, A Lamahewage}

Ceylon Medical Journal 2011; 56: 33

\section{Introduction}

Congenital anterior penile urethral fistula is a rare condition with less than 20 cases reported [1]. It is commonly associated with anorectal malformations, but isolated cases also have been reported [2,3]. We report a case of wide congenital anterior urethrocutaneous fistula associated with anorectal malformation.

\section{Case report}

A three-year old boy was admitted for repair of congenital urethral fistula. He was the only child to nonconsanguinous parents. At birth imperforate anus and congenital urethral fistula were detected. He had undergone colostomy at 2 days of age and posterior sagital anorectoplasty at the age of nine months. Colostomy closure had been done two months later. On examination a congenital urethral fistula of $3.4 \mathrm{~cm}$ long and $2.6 \mathrm{~cm}$ wide was noted (skin defect). The length of urethral defect was $2.4 \mathrm{~cm}$. The urethra distal to the fistula was normal with normal prepuce and glans (Figure 1). Proximal urethra was normal and there was no chordee. No previous penile surgery had been done.

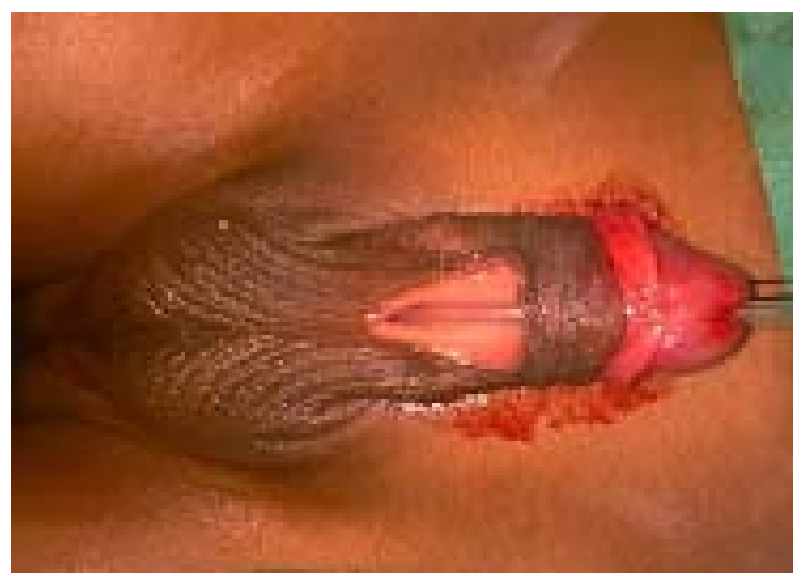

Figure 1. Large wide congenital urethral fistula with normal proximal urethra, prepuce and glans.

During surgery urethra was catheterised after cystoscopy. The incision was made at the margin of skin defect. Dartos fascial defect was identified just lateral to the skin defect. Urethroplasty was done over a catheter.
Separated corpus spongiosum was repaired over the neourethra. Dartos fascia and skin were sutured separately. Catheter was kept for 5 days. The repair was intact without a fistula one month after surgery.

\section{Discussion}

The external genital structures are identical in males and females until 8 weeks of gestation. The genitalia develop a masculine phenotype in males primarily under the influence of testosterone. As the phallus grows the open urethral groove extends from its base to the level of the corona. The classic theory is that the urethral folds coalesce in the midline from base to tip, forming a tubularised penile urethra and median scrotal raphe. This accounts for the posterior and middle urethra. The anterior or glanular urethra is thought to develop in a proximal direction, with an ectodermal core forming at the tip of the glans penis. This canalises and joins the more proximal urethra at the level of the corona. Focal or temporary defect in fusion of urethral folds may be the cause for this defect or it may be a part of a complex developmental anomaly associated with anorectal malformation [2,3].

Many techniques have been described to repair this defect. They include simple closure, as second stage of Johansson urethroplasty, buccal mucosal graft and or endoscopic repair $[4,5]$. As this patient's defect was wide and similar to hypospadias we used the anatomical repair of all layers as in the repair for hypospadias. It gave good cosmetic and functional results.

\section{References}

1. Sharma AK, Kothari SK, Goel D, Chaturvedi V. Congenital urethral fistula. Pediatric Surgery International 2000 16: 142-3.

2. Galinier P, Mouttalib S, Carfagna L, Vaysse P, Moscovici J. Congenital anterior urethrocutaneous fistula associated with stenosis of the bulbar urethra in the context of high anorectal malformation without fistula. Journal of Plastic Reconstructive Aesthetic Surgery 2009; 62: 11-3.

3. Harjai MM. Congenital urethrocutaneous fistula. Pediatric Surgery International 2000; 16: 386-7.

4. Betalli P, Carretto E, Midrio P, Zanon GF, Gamba PG. A new indication for buccal mucosal graft: isolated congenital fistula of the penile urethra. Pediatric Surgery International 2003; 19: 586-7.

5. Bedir S, Kilciler M, Ozgok Y. Case report: endoscopic treatment of isolated congenital urethroperineal fistula. Journal of Endourology 2006; 20: 42-4.

${ }^{1}$ Department of Paediatric Surgery, Lady Ridgeway Hospital for Children, Colombo, Sri Lanka.

Correspondence: TLAJK, e-mail <janathliyan@gmail.com>. Received 15 March and accepted 7 August 2010. Competing interests: none declared. 